\title{
A pancreatic tumour with carcinoid syndrome and hypoglycaemia
}

\author{
T. N. Appleyard \\ M.B., Ch.B. \\ Department of Medicine, \\ County Hospital, York
}

\author{
M. S. LosowsKY \\ M.D., F.R.C.P. \\ Department of Medicine, \\ University of Leeds
}

\section{Introduction}

In recent years it has become recognized that tumours of many organs may produce hormones normally originating in quite different organs and tissues and that these hormones may have endocrine effects on their target organs.

On occasion multiple tumours co-exist in different endocrine tissues in the same individual, constituting the multiple endocrine adenoma syndrome (Cooke et al., 1960). Alternatively a single tumour may elaborate more than one hormonal substance and produce diverse endocrinological effects (Shames, Dhurandhar \& Blackard, 1968), and this ability to produce multiple hormones probably reflects embryological potentialities of cells of a single tissue.

We report here a patient whose pancreatic tumour seemed capable of producing insulin, with consequent hypoglycaemia, and also serotonins, producing the carcinoid syndrome. In addition the fact that a large duodenal ulcer co-existed and the patient was a young female might suggest excessive gastrin production.

The value of arteriography is demonstrated both in showing the primary lesion in the pancreas and the extent of metastases in the liver.

\section{Case report}

A 22-year-old girl was admitted to hospital complaining of pain in the right hypochondrium for 2 weeks, nausea, vomiting, rather loose stools and loss of energy for 6 weeks and marked loss of weight for 4 months.

Examination revealed a pale thin girl with a dry flaking skin. The liver was palpable four finger breadths below the costal margin and was firm and smooth. There were no other significant physical signs. X-ray of the chest showed only a raised right diaphragm, and barium meal showed a large ulcer crater in the duodenum. She was treated with diet and bed-rest and by the following week the pain and

* Present address: Department of Medicine, St James's Hospital, Leeds LS9 7TF. vomiting had completely disappeared and she was allowed home.

She remained symptom-free until a week later when she was admitted as an emergency in coma which recovered soon after admission. The following morning she again became comatose, her blood sugar was found to be only $21 \mathrm{mg} / 100 \mathrm{ml}$, and she recovered dramatically after intravenous dextrose. Thereafter hypoglycaemia became more frequent and persistent in spite of diets with high carbohydrate and high fat content. In addition to the diet approximately $360 \mathrm{~g}$ of intravenous dextrose per day was required in order to maintain consciousness. Diazoxide (100-200 mg daily) and bendrofluazide (10 mg daily) were then given with dramatic improvement in hypoglycaemia. An attempt at gradual withdrawal of the diazoxide resulted in return of the hypoglycaemia which responded dramatically to re-institution of this drug (Fig. 1).

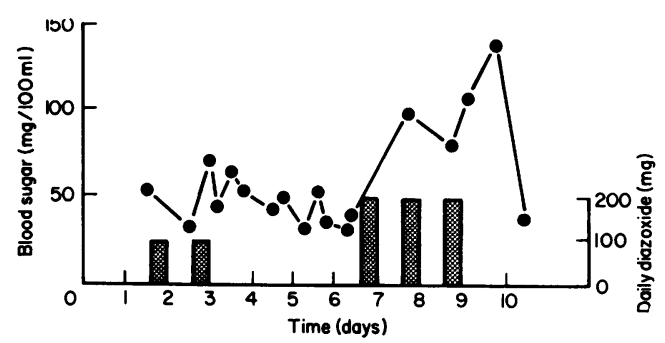

FIG. 1. Response of the blood sugar to diazoxide combined with bendrofluazide.

In view of the mild diarrhoea and absence of pathogens in the stools, urinary indoles were estimated and it was only after the results were obtained that typical flushing attacks started to occur.

After starting diazoxide her general condition improved dramatically and she started to gain strength and become mobile. Despite this there was increasing muscle wasting and neurological 
examination revealed signs suggestive of a peripheral neuropathy.

While apparently continuing to make good progress her condition suddenly deteriorated and the diarrhoea became more marked. In spite of treatment with antibiotics, nicotinic acid in large doses and chlorpromazine she died, 6 months after the onset of the illness.

Investigations. Total protein $5 \cdot 2 \mathrm{~g} / 100 \mathrm{ml}$, albumin $2.8 \mathrm{~g} / 100 \mathrm{ml}$, alkaline phosphatase $22 \mathrm{KA}$ units, thymol turbidity 4.0 units, total bilirubin $1.3 \mathrm{mg}$ / $100 \mathrm{ml}$, SGOT 86 units, SGPT 86 units, BSP retention $30 \%$ after $30 \mathrm{~min}$, blood urea $25 \mathrm{mg} / 100 \mathrm{ml}$, plasma cortisol $39.9 \mu \mathrm{g} / 100 \mathrm{ml}$ at 09.00 hours (normal 7-30 $\mu \mathrm{g} / 100 \mathrm{ml}$ ).

Urinary total 5-hydroxyindoles $230 \mathrm{mg} / 24 \mathrm{hr}$ (normal 2-8 $\mathrm{mg}$ ). Indole chromatogram: strong spots due to 5HIAA and 5-hydroxytryptamine present. Urinary creatine $970 \mathrm{mg} / 24 \mathrm{hr}$ (normal 0-100 mg). Urinary $N$-methyl nicotinamide $4.3 \mathrm{mg} /$ $24 \mathrm{hr}$ (normal 6-21 mg). Xanthurenic acid not detected in the urine. Urinary histamine excretion $15 \mathrm{mg} / 24 \mathrm{hr}$ (normal 15-90 mg). Urinary 17-oxysteroids, $4.0 \mathrm{mg} / 24 \mathrm{hr}$ (normal 3-15 mg), 17-ketogenic steroids $8.0 \mathrm{mg} / 24 \mathrm{hr}$ (normal 5-16 mg).

Serum insulin levels were measured by immunoassay on two occasions in the fasting state, values of $84 \mu \mathrm{U} / \mathrm{ml}$ and $78 \mu \mathrm{U} / \mathrm{ml}$ being found, the blood sugar levels being 21 and $75 \mathrm{mg} / 100 \mathrm{ml}$ (normal fasting plasma insulin levels up to $28 \mu \mathrm{U} / \mathrm{ml}$ ).

Coeliac and superior mesenteric arteriograms showed gross enlargement of the liver and areas with a vascular 'blush' characteristic of secondary deposits, in the right and left lobes. The pancreatic vessels showed a small circumscribed lesion about $2 \mathrm{~cm}$ in diameter in the tail of the pancreas.

Liver biopsy showed a moderately differentiated adenocarcinoma consistent either with an islet-cell tumour or a carcinoid tumour or a primary cholangiocarcinoma; silver staining gave negative results.

Motor point biopsy of the left peroneus brevis muscle showed gross atrophy in the form of groups of large numbers of equally narrowed fibres in contrast with a minority of fibres which were normal or hypertrophied and often rounded. No motor nerve supply was demonstrated presumably owing to gross neurogenic atrophy. Muscle spindles were of normal appearance in the paraffin section, and a nearby nerve (presumably sensory) was fully myelinated.

Necropsy. The pancreatic tumour, exactly the size and in the position shown by the arteriogram, was confirmed, together with numerous hepatic metastases. A large duodenal ulcer was present. All other organs were normal in appearance.

Histology of the pancreatic tumour showed an adenocarcinoma of variable appearance, most frequently composed of interlacing cords and solid acini of more or less columnar cells with vesicular nuclei and resembling those of the islets of Langerhans but in other areas there were groups with darker pyknotic nuclei and oesinophilic cytoplasm. Silver stains were negative. The morphology of the liver metastases was similar to the primary tumour in the pancreas.

\section{Discussion}

Hypoglycaemia may be due to primary tumours of the liver (Crawford, 1931; Nadler \& Wolfer, 1929; McFadzean \& Yeung, 1956; MacDonald, 1957; Klein \& Klein, 1959; Lowbeer, 1961), and this seemed possible in this patient even after liver biopsy. Arteriography was of great value in demonstrating the small pancreatic lesion and the extent of metastatic spread, and had the liver biopsy not demonstrated the tumour, arteriography would have obviated the need for laparotomy. In view of the primary pancreatic tumour and the high levels of insulin in the blood, this must be regarded as a functioning islet-cell tumour, despite the lack of $\beta$-cell granules (Marks \& Samols, 1966).

In this patient, however, there was also excess of 5-hydroxyindoles, and this might thus be termed an atypical carcinoid tumour (Oates \& Sjoerdsma, 1962) arising in the pancreas.

Multiple endocrine syndromes may be due to tumours of more than one endocrine organ (Cooke et al., 1960). In this case, however, no other tumour was found at necropsy despite careful search. Multiple endocrine syndromes may also result from a single tumour arising in an endocrine organ (or even such a tumour arising in a tissue which does not ordinarily have an endocrine function) (Peart et al., 1963; Van Der Sluys Veer et al., 1964). For example a single tumour may produce gastrin and insulin (Zollinger \& Elliott, 1959) or gastrin and parathyroid hormone (Dutta \& Wallace, 1968). Our patient appears to be only the third reported in whom the carcinoid syndrome has occurred secondary to an insulin-secreting islet-cell adenoma of the pancreas (Van Der Sluys Veer et al., 1964; Gloor, Pletscher \& Hardmeier, 1964). In view of the large duodenal ulcer, which is an unusual finding in a young female, it seems possible that the tumour may also have secreted gastrin or a gastrin-like peptide, but unfortunately no measurements relevant to this were made. It seems unlikely that the duodenal ulcer was secondary to stimulation of gastric secretion by hypoglycaemia (Marks \& Rose, 1965 ), since the ulcer was clearly demonstrated radiologically before the onset of symptoms of hypoglycaemia. The production of many hormones by a single tumour raises the interesting speculation that 
cells of endocrine tissues may be potentially biochemically multipotent, and that in the modifications resulting in tumour formation suppressed biochemical pathways might be re-established (Peart, 1966).

A further mechanism for the hypoglycaemia may also be considered. It has been shown (Silverstein, Wakim \& Bahn, 1966) that tryptophan metabolites can produce hypoglycaemia in mice and that levels of these metabolites may be increased in patients with tumours, particularly when associated with hypoglycaemia. Low blood sugars have been recorded in patients with carcinoid tumours (Kahler \& Heilmeyer, 1961; Schmid, Wenzl \& Uehlinger, 1963) but this does not seem to be more common or more severe than with tumours of other tissues when levels of 5-hydroxyindoles are not as high. It thus seems unlikely that the tryptophan metabolites themselves were the cause of the profound hypoglycaemia in this patient, particularly in view of the raised serum insulin levels.

In patients with the carcinoid syndrome, the excess production of 5-hydroxyindoles may divert tryptophan away from the formation of nicotinamide, and produce a clinical state resembling pellagra of nutritional origin. The diarrhoea, and the presence of skin changes in this patient would be consistent with this mechanism, and the excretion of $n$-methyl nicotinamide in the urine was below the lower limit of normal, providing biochemical confirmation. The absence of xanthurenic acid in the urine suggested that pyridoxine deficiency was unlikely to explain this finding.

Clinical examination of the nervous system suggested a peripheral neuropathy, and this was borne out by slowing of electrical conduction in the peripheral nerves and by the histological findings on motor point biopsy. Peripheral neuropathy is described in hypoglycaemia (British Medical Journal, 1964) and the muscle wasting and creatinuria in our patient may have been at least partly secondary to the peripheral neuropathy.

A further point of interest was the prompt and dramatic response of the otherwise intractable hypoglycaemia to diazoxide (Fig. 1). There is some evidence that one mechanism of action of diazoxide may be to inhibit the secretion of insulin (Grant, Piesowicz \& Buckler, 1966; Howell \& Taylor, 1966). If this were the case, there might be considerable implications for the biochemical control of these and other endocrine syndromes produced by tumours.

\section{Acknowledgments}

We are grateful to Dr H. Herlinger for the arteriograms and to Professor Russell Fraser for the serum insulin estimations.

\section{References}

British Medical Journal (1964) Diabetes and neuropathy. 2, 891.

COOKe, W.T., Fowler, D.I., GADdIE, R., CoX, E.V., Meynell, M.J. \& BreWer, D. (1960) Multiple endocrine adenoma syndrome. Gut, $1,71$.

Crawford, W.H. (1931) Hypoglycaemia with coma in a case of primary carcinoma of the liver. American Journal of the Medical Sciences, 181, 496.

Dutra, P. \& Wallace, M.R. (1968) Familial multiple endocrine adenopathy (primary hyperparathyroidism and Zollinger-Ellison syndrome) in two siblings. Proceedings of the Royal Society of Medicine, 61, 658.

Gloor, F., Pletscher, A. \& Hardmeier, T. (1964) Metastatic islet cell tumour of the pancreas with 5 hydroxytryptamine and insulin production. Schweizerische medizinische Wochenschrift, 94, 1476.

Grant, D.S., Piesowicz, A.T. \& Buckler, J.M.H. (1966) Effect of treatment with Diazoxide and chlorothiazide on a child with leucine-sensitive hypoglycaemia. British Medical Journal, 2, 1494.

Howell, S.L. \& TAYloR, K.W. (1966) Preliminary communication. Effects of diazoxide on insulin secretion in vitro. Lancet, $\mathbf{i}, 128$.

KAHLER, H. \& HeILMEYeR, L. (1961) Clinical aspects and pathophysiology of carcinoid and carcinoid syndrome with special reference to the pharmacology of 5 : Hydroxytryptamine. Ergebnisse innere Medizin und Kinderheilkunde, 16, 292.

KLEIN, H. \& KLeIN, S.P. (1959) Spontaneous hypoglycaemia associated with massive hepatoma. Archives of Internal Medicine, 103, 273.

LOWBEER, L. (1961) Hypoglycaemia-producing extrapancreatic neoplasms. American Journal of Clinical Pathology, 35, 233.

MacDonald, R.A. (1957) Primary carcinoma of the liver Archives of Internal Medicine, 99, 266.

MARks, V. \& Rose, F.C. (1965) Hypoglycaemia. Blackwell Scientific Publications, Oxford and Edinburgh.

Marks, V. \& SAmols, E. (1966) Non islet cell neoplasms associated with spontaneous hypoglycaemia in man. Proceedings of the Royal Society of Medicine, 59, 338.

McFadzean, A.J.S. \& Yeung, T.T. (1956) Hypoglycaemia in primary carcinoma of the liver. Archives of Internal Medicine, 98, 720.

NADLER, W.H. \& Wolfer, Y.A. (1929) Hepatogenic hypoglycaemia associated with primary liver cell carcinoma. Archives of Internal Medicine, 44, 700.

OAtes, J.A. \& SJoerdsma, A. (1962) A unique syndrome associated with secretion of $5:$ Hydroxytryptamine by metastatic gastric carcinoids. American Journal of Medicine, 32, 333.

Peart, W.S., Porter, K.A., Robertson, J.S., SAndler, M. \& BALDOCK, E. (1963) Carcinoid syndrome due to pancreatic duct neoplasm secreting 5 : Hydroxytryptophan and 5 : Hydroxytryptamine. Lancet, i, 239.

Peart, W.S. (1966) Carcinoid tumours. Acta medica Scandinavica, 179, Suppl. 445, 371.

SChmid, M., Wenzl, H. \& Uehlinger, E. (1963) B islet cell carcinoma of the pancreas with hypoglycaemia combined with multiple carcinoid tumours of the ileum. Schweizerische medizinische Wochenschrift, 93, 444.

Shames, J.M., Dhurandhar, N.R. \& Blackard, W.G. (1968) Insulin-secreting carcinoid tumour with widespread metastases. American Journal of Medicine, 44, 632.

Silverstein, M.N., WaKim, K.G. \& BaHN, R.C. (1966) Role of tryptophan metabolites in the hypoglycaemia associated with neoplasia. Cancer, 19, 127. 
Van der Sluys Veer, J., Choufoer, J.C., Querido, A., VAN Der Heul, R.O., Hollander, C.F. \& VAN RiJssel, T.G. (1964) Metastasizing islet cell tumour of the pancreas associated with hypoglycaemia and carcinoid syndrome.
Lancet, i, 1416.

Zollinger, R.M. \& Elliott, D.W. (1959) Pancreatic endocrine function and peptic ulceration. Gastroenterology, 37, 401 .

\section{Macroglossia, abnormal umbilicus and hypoglycaemia (Beckwith's syndrome)}

\author{
M. W. MONCRIEFF* \\ M.A., B.M., M.R.C.P. \\ Lecturer in Paediatrics, \\ University of Birmingham
}

\author{
A. R. Goldsmith \\ M.B.B.S. \\ Registrar in Pathology, \\ Birmingham Children's Hospital
}

\author{
J. R. MANN \\ M.B., M.R.C.P., D.C.H. \\ Registrar in Paediatrics, \\ Birmingham Children's Hospital \\ G. W. Chance \\ M.B., M.R.C.P., D.C.H. \\ Senior Lecturer in Paediatrics, \\ University of Birmingham
}

\section{Introduction}

The syndrome of exomphalos, macroglossia, postnatal somatic gigantism and severe hypoglycaemia in various combinations was first described in seven infants by Beckwith (1963) and Beckwith et al. (1964). At necropsy the main features were cytomegaly of the foetal adrenal cortex, renal medullary dysplasia, and hyperplasia of the pancreas and kidneys. Wiedemann (1964) reported three siblings of a consanguineous marriage who had macroglossia and exomphalos. The survivor developed post-natal somatic gigantism and accelerated bone growth. Irving (1967) reported eleven children with exomphalos and macroglossia, nine of whom had a birth weight on or above the 90th centile for their gestational age. Ten of the children had a facial naevus, seven had a linear indentation of the ear lobe and three had a dome-like elevation of the posterior part of the diaphragm. The six surviving children developed a characteristic facies with prognathos, mid-facial under development and slight exophthalmos, and a mid-line frontal ridge. Postnatal somatic gigantism occurred in five of the six survivors. A further seven cases with macroglossia and umbilical abnormality were reported by Shafer (1968). Severe hypoglycaemia and birth weight above the mean for their gestational age were the main features of the three cases reported by Combs, Grunt \& Brandt (1966). The principal features of the previously reported cases are shown in Table 1.

Two further cases are reported who developed hypocalcaemia, in addition to the main features already described. One survived and now has hemihypertrophy.

TABLE 1. The main features of Beckwith's syndrome (not all are present in every case)

\begin{tabular}{lll}
\hline \multicolumn{1}{c}{ Birth } & \multicolumn{1}{c}{ Childhood } & \multicolumn{1}{c}{ Necropsy } \\
\hline Macroglossia* & Post-natal gigantism* & Cytomegaly of foetal \\
Abnormal umbilicus* & Characteristic facies* & adrenal cortex* \\
Somatic gigantism* & Microcephaly* & Renal medullary \\
Facial naevus* & Mental retardation* & dysplasia* \\
Hypoglycaemia* & Hemihypertrophy & Hyperplasia of: \\
Enlarged kidneys* & Malignant disease & Pancreas* \\
Enlarged liver* & & Kidneys* \\
Ear lobe anomaly & & \\
Abnormality of the diaphragm & & \\
Hypocalcaemia & & \\
Polycythaemia & & \\
\hline
\end{tabular}

* Commonly found

* Now Consultant Paediatrician, Derby Children's Hospital. 